Article

\title{
Exploring the Decisive Risks of Green Development Projects by Adopting Social Network Analysis under Stakeholder Theory
}

\author{
Li Ma ${ }^{1,2}$, Lin Wang ${ }^{1,3}$, Kuo-Jui $\mathrm{Wu}^{2, *} \mathbb{1}$, Ming-Lang Tseng ${ }^{2,4}$ (1) and Anthony S. F. Chiu ${ }^{5}$ \\ 1 Department of Construction Management, Dalian University of Technology, Dalian 116024, China; \\ cm_mali@dlut.edu.cn (L.M.); wanglin0104208@163.com (L.W.) \\ 2 School of Business, Dalian University of Technology, Panjin 124221, China; tsengminglang@gmail.com \\ 3 Department of Civil Engineering, Beihua University, Jilin 132013, China \\ 4 Institute of Innovation and Circular Economy, Asia University, Taichung 41354, Taiwan \\ 5 Department of Industrial Engineering, De La Salle University, Manila 1004, Philippines; \\ anthonysfchiu@gmail.com \\ * Correspondence: wukuojui@dlut.edu.cn; Tel.: +86-138-0427-6853
}

Received: 23 April 2018; Accepted: 17 June 2018; Published: 20 June 2018

\begin{abstract}
The Belt and Road initiatives related to green development projects are being increasingly considered globally. However, such projects face several risks resulting from stakeholder diversity. Although previous studies attempted to identify the risks caused by stakeholders, they found it difficult to provide a precise boundary to separate the risks attributable to a single stakeholder. This study adopts social network analysis to explore the decisive risks attributed to each stakeholder by considering a project's stage. The results reveal that contractors take on the most risk and, thus, require real-time monitoring. Furthermore, all stakeholders need to collaborate with one another during the implementation stage of a project to mitigate the occurrence of risk. This study makes three contributions: it (1) provides a theoretical basis for enhancing the understanding of stakeholder theory; (2) offers specific guidelines for monitoring risks; and (3) enables stakeholders to understand their duties in controlling risks. Detailed discussions are provided in the remainder of the manuscript.
\end{abstract}

Keywords: stakeholder theory; green development project; risk; social network analysis

\section{Introduction}

Belt and Road initiatives are increasing in popularity throughout the world. Thus, developing countries want China to provide technology to improve their infrastructure, such as the Karot hydropower station project in Pakistan. Moreover, the Northeast of China was a famous old industrial area that generated lots of equipment for infrastructure development. However, infrastructure development requires more green development projects to achieve sustainability. Although these projects not only generate economic growth but also promote sustainable development [1], an appropriate approach to assess the risks and uncertainties associated with such projects is lacking. These risks and uncertainties are commonly caused by stakeholders, a concept that has been omitted in previous studies. Moreover, stakeholders might cause the decision maker to make an incorrect resource utilization decision related to green development.

Stakeholder theory was developed by Mitchell et al. [2] to manage and categorize stakeholders' saliency in terms of the related absence of power, legitimacy, and persistence and to address how managers handle stakeholders' claim priorities. Thus, studies have attempted to determine the relationships among stakeholders to prevent the occurrence of risks during project implementation. Yang et al. [3] integrated decisive risk management processes using a social network method to 
investigate the correlations among stakeholders. Yang and Zou [4] adopted a stakeholder risk analysis to assess the interactions among green development projects. Zhao et al. [5] applied a fuzzy synthetic analysis to develop a risk evaluation model to provide on-time, efficient, and reliable evaluations. Hwang et al. [6] conducted a comprehensive literature review and engaged in structured interviews to identify and evaluate the risk factors in green development projects and compare their critical risks with those in traditional projects and to propose mitigation measures that can address these risk factors. To clearly distinguish the risk factors among stakeholders, this study adopts five main groups, including owner, contractor, designer, supervisor and government, to facilitate further discussion.

Moreover, green development projects have increased rapidly over the past two decades. However, efforts to link risk assessments with the stakeholders in these projects remain limited. The current risk assessments of green development projects remain insufficient because they are not extensive enough to reflect real problems, and assessment tools require a combination of qualitative and quantitative data to allow engagement in deeper discussions [7]. In addition, the interactions among stakeholders are often neglected in previous studies [3]. Although several studies have attempted to develop a risk assessment framework for green development projects, methods to prevent occurrences of risk from stakeholders' point of view are lacking [8]. In addition, the interactions among stakeholders are not yet well discussed [9].

Yang et al. [3] applied stakeholder-associated risk networks to compare the differences between Chinese and Australian green development projects. Yang et al. [10] utilized a non-dominated sorting genetic algorithm to explore a multi-objective optimization design for green development. To assess the risks regarding stakeholders, the algorithm relies on a multidimensional approach [11]. Previous studies often used quantitative data to assess a project's performance and the potential risks; however, they failed to consider qualitative data that reflect the real situation. Accordingly, this study attempts to fill this gap by applying SNA to explore the critical risks among stakeholders.

To prevent such an occurrence, in this study, stakeholder theory in association with social network analysis (SNA) is proposed as a strategy to address these issues and mitigate risks and uncertainties. SNA is a conceptual network representation that enables stakeholder relationships to be arranged using nodes and links (edges in graph theory) based on specific types of social interactions [12]. Moreover, risks exist within the interrelations in reality. To consider these interrelations, SNA provides an efficient way to assess the complexity of a green development project [4]. Most of the current risk assessment approaches are based on the identification of risk factors. However, such assessments do not consider the interrelations among stakeholders during a project and lack intuitive and quantitative methods to analyze the correlations among stakeholders [13].

Therefore, the objective of this study is to explore the critical risks of green development projects by considering stakeholders' interrelations through the adoption of SNA. This study makes three contributions. First, the findings provide a theoretical basis for enhancing the understanding of stakeholder theory in project-oriented cases. Second, the proposed method distills problems into a focal point, which offers a precise guideline for Belt and Road firms with respect to green development. Third, the precise guideline allows firms to improve their performance with limited resources. The remainder of this study is structured as follows: Section 2 provides a detailed discussion of the method and the proposed analytical procedures. The empirical results are discussed in Section 3. Theoretical and managerial implications are presented in Section 4. The final section provides the conclusions, research limitations, and directions for future studies.

\section{Materials and Method}

This section introduces the questionnaire formulation, data integration using SNA, and proposed analytical procedures.

\subsection{Questionnaire}

Five stakeholders were selected to investigate the risks related to the proposed measures: the owner, contractor, designer, supervisor, and government. Furthermore, there are fifty-four risks 
arranged under these five stakeholders (as shown in Table 1). To provide an extensive and comparable scale for the respondents, the questionnaire adopts a seven-point assessment scale. A lower number represents a weaker influence on a green development project's risk. The assessments rely on the professional knowledge and work experience of the respondents in a related industry.

Table 1. Proposed measures.

\begin{tabular}{|c|c|c|}
\hline Stakeholders & & Risks \\
\hline Owner & $\begin{array}{l}\text { C1 } \\
\text { C2 } \\
\text { C3 } \\
\text { C4 } \\
\text { C5 } \\
\text { C6 } \\
\text { C7 } \\
\text { C8 } \\
\text { C9 } \\
\text { C10 } \\
\text { C11 } \\
\text { C12 } \\
\text { C13 } \\
\text { C14 } \\
\text { C15 } \\
\text { C16 } \\
\text { C17 } \\
\text { C18 } \\
\text { C19 }\end{array}$ & $\begin{array}{l}\text { Issues of project funding } \\
\text { Owner's requirements } \\
\text { Owner's green development investment was underestimated } \\
\text { Unreasonable schedule requirements } \\
\text { Inaccurate location of the project } \\
\text { Owner is inefficient } \\
\text { Owner makes unreasonable interventions during the process } \\
\text { Conflicts with owner's requirements } \\
\text { Insufficient consideration across project requirements } \\
\text { Insufficient communication to coordinate participants in the project } \\
\text { Operations are unable to meet the regulations and achieve green certification } \\
\text { Evaluation results are unable to reach the level of green certification } \\
\text { Vague responsibilities } \\
\text { Certification risk causes incomplete declaration of materials } \\
\text { Project contract defects and changes result in claims } \\
\text { Lack of property management experience causes operational damage } \\
\text { Project demand and market share are overforecast } \\
\text { Project is unstable and lacks scientific maintenance } \\
\text { Lack of green development insurance products }\end{array}$ \\
\hline Contractor & $\begin{array}{l}\text { C20 } \\
\text { C21 } \\
\text { C22 } \\
\text { C23 } \\
\text { C24 } \\
\text { C25 } \\
\text { C26 } \\
\text { C27 } \\
\text { C28 } \\
\text { C29 } \\
\text { C30 } \\
\text { C31 } \\
\text { C32 } \\
\text { C33 } \\
\text { C34 } \\
\text { C35 } \\
\text { C36 } \\
\text { C37 } \\
\text { C38 } \\
\text { C39 } \\
\text { C }\end{array}$ & $\begin{array}{l}\text { Poor management ability } \\
\text { Failing to reach the green certification goal and causing claims } \\
\text { Underestimating the cost of the project and increasing the quoted price } \\
\text { Lack of experience managing technical personnel } \\
\text { Insufficient experience adopting new materials, technologies, and equipment } \\
\text { Insufficient knowledge of green development projects } \\
\text { Insufficient understanding of requirements, causing default } \\
\text { Poor feasibility of the construction method } \\
\text { Unstable performance of new materials and equipment } \\
\text { Turnover rate is too high } \\
\text { Unclear responsibilities among the subcontractors } \\
\text { Insufficient documentation of green materials } \\
\text { Lack of coordination with the designer } \\
\text { Increased construction difficulty generates security risk } \\
\text { Project requirements cause overdue risk } \\
\text { Scarce green materials drive up green product prices } \\
\text { Additional requirements for a trial operation } \\
\text { Lack of insurance for staff and equipment } \\
\text { Shortage of insurance for staff and equipment } \\
\text { Warranty risk } \\
\text { Lack of project insurance }\end{array}$ \\
\hline Designer & $\begin{array}{l}\text { C41 } \\
\text { C42 } \\
\text { C43 } \\
\text { C44 } \\
\text { C45 } \\
\text { C46 } \\
\text { C47 } \\
\text { C48 }\end{array}$ & $\begin{array}{l}\text { Design flaws } \\
\text { Design changes } \\
\text { Insufficient design integration experience for the project } \\
\text { Eco-design innovation risk } \\
\text { Insufficient innovation in construction and design } \\
\text { Inaccurate cost estimation } \\
\text { Insufficient on-site investigation results in a design that does not match real conditions } \\
\text { Lack of lifecycle assessment in the design }\end{array}$ \\
\hline Supervisor & $\begin{array}{l}\text { C49 } \\
\text { C50 } \\
\text { C51 } \\
\text { C52 }\end{array}$ & $\begin{array}{l}\text { Lack of experience in green development project supervision } \\
\text { Inadequate understanding of green development projects } \\
\text { Insufficient data collection and monitoring } \\
\text { Nonstandard supervision behavior }\end{array}$ \\
\hline Government & $\begin{array}{l}\text { C53 } \\
\text { C54 } \\
\text { C55 } \\
\text { C56 } \\
\text { C57 }\end{array}$ & $\begin{array}{l}\text { Overly expensive examination and approval procedures } \\
\text { Government intervenes unreasonably } \\
\text { Incomplete laws and regulations } \\
\text { Lack of relevant special clause to encourage a green development project } \\
\text { Policy changes }\end{array}$ \\
\hline
\end{tabular}




\subsection{Data Integration with $S N A$}

\subsubsection{Network Density}

Network density is defined as the ratio of the actual number of connections to the maximum number of theoretical correlations and is calculated as follows:

When the network is an indirect network:

$$
D E=2 p / q(q-1)
$$

When the network is a directed network:

$$
D E=p / q(q-1)
$$

where $p$ indicates the actual correlation numbers, and $q$ represents the actors or vertexes. When the network density is greater, the influence of the network on the attitude and behavior of the actors is greater. A network that is closely linked not only provides social resources but also significantly constrains the development of the actors [14]. Higher density has greater effects on behaviors. In addition, assessing the degree of density helps identify regular internal patterns and decisive risks.

\subsubsection{Degree Distribution}

A vertex's degree represents the number of edges that are connected to vertex $i$. The average of the degrees in a network can be written as $\langle D E\rangle$. In a directed network, the degrees of vertexes can be categorized into out-degree and in-degree vertexes. The out-degree of vertex $i$ is the quantity of arcs that start from vertex $i$ that point to other vertexes. The in-degree of vertex $i$ is the number of arcs that start from other vertexes and end at vertex $i$. The point degree is defined as the number of lines that the vertexes contain and is represented as follows:

$$
D E_{i}=\sum_{j} l_{i j}+\sum_{j} l_{j i}
$$

The average degree can be defined as follows:

$$
\langle D E\rangle=\frac{1}{q} \sum_{i} D E_{i j}=\frac{1}{q} \sum_{i j} l_{i j}
$$

The maximum degree can be defined as follows:

$$
D E_{\max }=\max D E_{i}
$$

A degree distribution describes the number of points within the network. For a random network, the degree distribution refers to the probability distribution of the vertex degree in the graph. If using the frequency instead of the probability, the degree distribution can be classified as the in-degree and the out-degree frequency distribution. These distributions reveal the correlations among the risks, which provide the basis to explore the decisive risks.

\subsubsection{Centrality Analysis of Network-Centrality and Centralization}

Centrality refers to the measure of the degree to which each vertex is at the center of the network in a quantitative manner. Centrality mainly shows the degree centrality and the extent of the centralization. Centrality theory states that the center point has the maximum degree of vertexes in the network. Therefore, the center degree can be computed as follows:

$$
C_{D E}(x)=D E(x) /(q-1)
$$


where $D E(x)$ denotes the degree of $x, q$ denotes the total number of nodes in the network, and $q-1$ denotes the maximum number of possible neighbors.

After determining the degree centrality of the network, each vertex is arrayed to determine the influence of the network. The extent of the center $C_{D E}^{g}$ can be calculated as follows:

$$
C_{D E}^{g}=\frac{\sum_{X \epsilon N}\left(C_{D E}^{*}-C_{D E}(x)\right)}{(q-1) \max \left(C_{D E}^{*}-C_{D E}(x)\right)}
$$

where $q$ represents the network to which the vertexes belong, and $C_{D E}^{*}=\max _{D E}(x)$ represents the center value of the node that has largest degree of centrality. When $C_{D E}^{g}$ is smaller, the extent of network centralization will be weaker, and the difference in the vertexes in the network will be smaller. Conversely, more decentralization has more network centralization [14]. This approach can be used to determine the central point that affects the target network and offers a basis to purify the decisive risks.

\subsubsection{Quantitative Analysis of Network Cohesion-K-Core}

The majority of studies of complex networks only focus on macroscopic statistical analysis. However, it is difficult to ensure that the sample size is sufficient due to the contingency of the data and time limitations. Topological description theory combines macro statistical analysis with structural description theory to explain some phenomena more scientifically. $K$-core analysis is an efficient graphical method for analyzing a phenomenon as, in a sense, a type of node. Generally, the calculation of the vertex degree can only reveal the local connections of a single vertex, but it cannot explain the degree of condensation and dispersion of all the vertexes with higher degrees along the entire network. The $K$-core presents the maximum set of subnetworks that are not less than the value of $K$ [14]. Based on the value of $K$, the network can be simplified into a cohesive group to reflect the internal standard.

\subsubsection{Network Dependency Analysis-Island}

An island is a subnetwork defined by multiple values or lines of attachment. An island possesses the largest subnetwork if it meets the following condition: the various vertexes in the subnetwork are directly or indirectly connected, and the internal connection value is greater than the outer vertex of the subnetwork. Once the top line adhesive value on the vertex is taken as the altitude of the vertex, the island is similar to a local peak network. Following this analogy, the similarities and differences between the islands and the surrounding structures can be shown, further reflecting the structure and laws of the network [14]. Moreover, an island can present the subordination of each risk to screen out the critical risks. Thus, the decisive risks possess the features of higher degrees of density (obtained from Section 2.2.2) and centrality (generated from Section 2.2.3) and an island (gathered from Sections 2.2.4 and 2.2.5).

\subsection{Proposed Analytical Procedures}

1. Identify the boundary of the network; this step requires analyzing the reliability of the questionnaire through a significance test and a correlation analysis. Next, the risk correlations in the green development project based on the proposed measures are identified.

2. From the SNA, stakeholders are arranged by risk correlation in the green development project, which then provides a visualization of the risk correlations.

3. The correlations among the risks can be expressed by the lines between the points in the social network, which are presented as edges. A direct edge is called an arc. Therefore, the risk factors and the risk correlations can be described by a social network diagram. Based on the risk correlations, Pajek software is used to draw a non-weighted directed diagram with 54 vertexes.

4. Using SPSS22 statistical software and Pajek software, the network parameters of the risk correlations are calculated. 
5. K-core is a quantitative analysis of the network's cohesion and seeks the risk correlation. The island represents a network dependency analysis of the project's risk network. The controllable decisive risks that affect the global risk correlation are then identified. From the perspective of the correlation among the risks and based on the relevant parameters of the calculation, the key controllable risks in the green development project are extracted, and risk management strategies are proposed.

\section{Empirical Results}

This section provides the background of the case and the analytical results to support deeper discussion.

\subsection{Case Background}

Northeast China plays an important role in China's military and political positioning (as shown in Figure 1). This area connects three countries, Russia, Mongolia and North Korea, with Bi-Hai Bay. Therein, crude oil is delivered from Daqing, China to Tayshet and Nakhcidka, Russia, and another oil pipeline is under construction to Irkutsk, Russia. In addition, the Chinese government will increase the number of entry points from two to four to promote business activities in the area. The present value of Northeast China is clear given the nuclear issue with North Korea.

Green projects in China are being aggressively pursued. Preliminary achievements have been made in the fields of policy making, evaluation, and technology, which have led to several demonstration projects in various areas. However, the green projects are still in their initial stages, and the majority of small green development projects are mainly concentrated in coastal and economically developed areas. Many difficulties and obstacles exist to promoting green development in Northeast China (shown in Figure 1). Thus, this study adopts this area as its main case for exploring the decisive risks when encouraging green development by considering that stakeholders guide green development firms in making accurate decisions to mitigate risks and uncertainties.

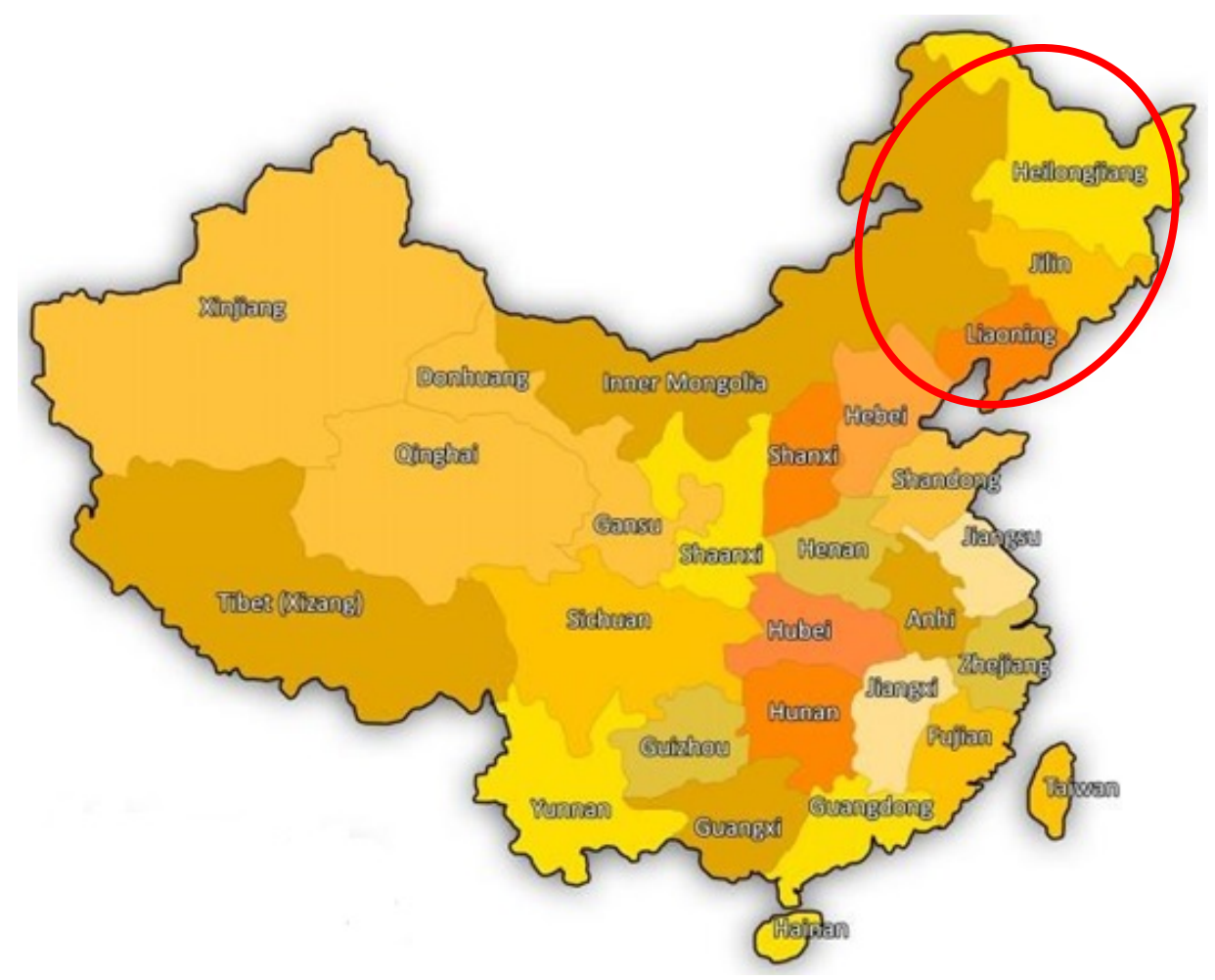

Figure 1. Northeast region of China. 


\subsection{Analytical Results}

1. The period under investigation is between 1 July 2016, and 26 January 2017, and the invited respondents include academic and technical personnel from Jilin, Heilongjiang, and Liaoning provinces, as indicated in Figure 1. In the pilot study, 94 respondents were invited to join the assessment, and 91 responded. Of these 91, only 85 questionnaires were valid, for a validated return rate of $90 \%$. Based on the results of the pilot study, non-significant items were deleted from the initial questionnaire to enhance its reliability and validity. In the following stage, 400 revised questionnaires were distributed, and 312 were returned, with 285 valid respondents (71.25\% validated return rate). The questionnaire adopted a random distribution but screened out the area, concentrating only on respondents from Jilin, Heilongiiang, and Liaoning provinces, by using IP selection.

2. Moreover, owner, contractor, designer, supervisor and government are considered the main groups of green development projects. Therefore, this study distributed the questionnaire based on these five groups as categorized in previous studies. Table 2 shows the detailed information of the respondents. Then, the seven sub-items of the working unit are merged into the five main groups of owner, contractor, designer, supervisor and government to focus the discussion.

Table 2. Respondent Information.

\begin{tabular}{cccc}
\hline & Items & Frequencies & Percentage \\
\hline \multirow{2}{*}{ Age } & 25 and under & 39 & $12.26 \%$ \\
& $26-35$ years old & 134 & $42.14 \%$ \\
& $36-45$ years old & 66 & $20.75 \%$ \\
& $46-55$ years old & 76 & $23.9 \%$ \\
& 56 years old and above & 3 & $0.94 \%$ \\
\hline \multirow{3}{*}{ Working Experience } & 5 years and below & 34 & $10.69 \%$ \\
& $6-10$ years & 80 & $25.16 \%$ \\
& $11-15$ years & 139 & $47.31 \%$ \\
& $16-20$ years & 22 & $6.92 \%$ \\
& more than 20 years & 43 & $13.52 \%$ \\
\hline Working Unit & University & 61 & $19.18 \%$ \\
& Government Department & 31 & $9.75 \%$ \\
& Tender office & 6 & $1.89 \%$ \\
& Construction unit & 30 & $9.43 \%$ \\
Number of Green & Design Unit & 49 & $15.41 \%$ \\
Construction unit & 41 & $12.89 \%$ \\
& Consultant (including supervision) & 5 & $1.57 \%$ \\
& Other & 95 & $29.87 \%$ \\
\hline
\end{tabular}

3. Subsequently, Statistical Product and Service Solutions 22 was employed to calculate the overall Cronbach's alpha coefficient of 0.989 , which is greater than 0.9 . This result shows that the entire questionnaire possesses good reliability. The Cronbach's alpha coefficients for each subsection are shown in Table 3. 
Table 3. Cronbach's alpha coefficients for all stakeholders.

\begin{tabular}{cc}
\hline Stakeholders & Cronbach's Alpha \\
\hline Overall Scale & 0.989 \\
The risk consideration of the owner & 0.969 \\
The risk consideration of the contractor & 0.977 \\
The risk consideration of the designer & 0.957 \\
The risk consideration of the supervisor & 0.921 \\
The risk consideration of the government & 0.932 \\
\hline
\end{tabular}

4. Spearman correlation coefficients present the correlations among the 57 risks related to green development projects (as shown in Appendix A). All values reach a significance level of 0.01, except for the items with values of 1.000. This correlation table establishes six levels to classify the relationships: $\left|r_{i j}\right|=0$ means that two factors have no relationship; $0.3 \leq\left|r_{i j}\right|<0.5$ represents a lower relationship; $0.5 \leq\left|r_{i j}\right|<0.8$ represents a medium relationship; $0.8 \leq\left|r_{i j}\right|<1$ represents a higher relationship; and $\left|r_{i j}\right|=1$ indicates a complete relationship.

5. The lines of the vertexes in the social network indicate the correlations among the risk factors and are called edges. The transformation of the risk correlations can indicate the weight of the edges. Figure 2 shows the nondirected weighted diagram with 57 vertexes and 1462 edges by applying Pajek software.

6. Adopting Equation (1) to compute the density of the network, $D E=\frac{2 P}{q(q-1)}=0.916$. Subsequently, the average degree of the risk correlation of the network is obtained using Equations (3)-(5); the results show that $\langle D E\rangle=49.193$ and $k_{\max }=55$. Furthermore, by employing Pajek software, the degree and frequency for each node in the risk network can be calculated, as shown in Table 4 .

Table 4. Frequency distribution of risks.

\begin{tabular}{cccccc}
\hline Degree & Frequency & Frequency (\%) & $\begin{array}{c}\text { Accumulating } \\
\text { Frequency }\end{array}$ & $\begin{array}{c}\text { Accumulating } \\
\text { Frequency (\%) }\end{array}$ & Risks \\
\hline 14 & 1 & 1.7544 & 1 & 1.7544 & C2 \\
19 & 1 & 1.7544 & 2 & 3.5088 & C1 \\
36 & 2 & 3.5088 & 4 & 7.0175 & C6, C7 \\
38 & 1 & 1.7544 & 5 & 8.7719 & C3 \\
39 & 1 & 1.7544 & 6 & 10.5263 & C 44 \\
43 & 1 & 1.7544 & 7 & 12.2807 & C50, C56 \\
45 & 2 & 3.5088 & 9 & 15.7895 & C51 \\
46 & 1 & 1.7544 & 10 & 17.5439 & C5, C8, C12, C19, C57 \\
48 & 5 & 8.7719 & 15 & 26.3158 & C11, C53, C54 \\
49 & 3 & 5.2632 & 18 & 31.5789 & C14, C29, C40, C55 \\
50 & 4 & 7.0175 & 22 & 38.5965 & C35, C37, C47, C49 \\
51 & 4 & 7.0175 & 26 & 45.614 & C4, C10, C13, C16, C17, C18, \\
52 & 11 & 19.2982 & 37 & 64.9123 & C30, C36, C38, C39, C43 \\
53 & 4 & 7.0175 & 41 & 71.9298 & C9, C20, C23, C26 \\
54 & 12 & 21.0526 & 53 & 92.9825 & C15, C21, C24, C25, C27, C31, \\
55 & 4 & 7.0175 & 57 & 100.0000 & C32, C34, C42, C45, C46, C48 \\
Subtotal & 57 & 100.0000 & & & C22, C28, C33, C41 \\
\hline
\end{tabular}

7. Equations (6) and (7) are utilized to generate the extent of the centralization, as $C_{D E}^{g}=$ $\frac{\sum_{X \in N}\left(C_{D E}^{*}-C_{D E}(x)\right)}{(q-1) \max \left(C_{D E}^{*}-C_{D E}(x)\right)}=\frac{5.53}{(56 \times 0.71)} \approx 0.139$. Then, adopting K-core enables an exploration of the undirected network risk, which extracts a 43-core network with 50 vertexes. This 43 -core network can be isolated into four islands, as shown in Table 5. The four islands are presented in Figure 2 to clarify the correlations among the networks. Then, the networks can be used 
to identify the controllable key risks with higher degree values, higher degrees of centrality, and island values within the control process of a single stakeholder, as shown in Figure 3.

Table 5. Island information for the 43-core risk network.

\begin{tabular}{cccc}
\hline $\begin{array}{c}\text { Island } \\
\text { Label }\end{array}$ & $\begin{array}{c}\text { Island Value } \\
\text { (Altitude) }\end{array}$ & $\begin{array}{c}\text { Number of } \\
\text { Vertexes }\end{array}$ & Vertex Label \\
\hline $\mathrm{A}$ & 0.675 & 10 & $\mathrm{C} 5, \mathrm{C} 8, \mathrm{C} 9, \mathrm{C} 10, \mathrm{C} 11, \mathrm{C} 12, \mathrm{C} 13, \mathrm{C} 14, \mathrm{C} 15, \mathrm{C} 16$ \\
\hline $\mathrm{B}$ & 0.689 & 2 & $\mathrm{C} 17, \mathrm{C} 18$ \\
\hline $\mathrm{C}$ & 0.758 & 4 & $\mathrm{C} 37, \mathrm{C} 38, \mathrm{C} 39, \mathrm{C} 40$ \\
\hline $\mathrm{D}$ & 0.698 & 30 & $\mathrm{C} 21, \mathrm{C} 32, \mathrm{C} 32, \mathrm{C} 23, \mathrm{C} 34, \mathrm{C} 24, \mathrm{C} 25, \mathrm{C} 26, \mathrm{C} 27, \mathrm{C} 28, \mathrm{C} 29, \mathrm{C} 30, \mathrm{C} 31, \mathrm{C} 41, \mathrm{C} 42, \mathrm{C} 43, \mathrm{C} 44, \mathrm{C} 45, \mathrm{C} 46$, \\
& & & $\mathrm{C} 47, \mathrm{C} 48, \mathrm{C} 49, \mathrm{C} 50, \mathrm{C} 51, \mathrm{C} 53, \mathrm{C} 55, \mathrm{C} 56, \mathrm{C} 57$ \\
\hline
\end{tabular}
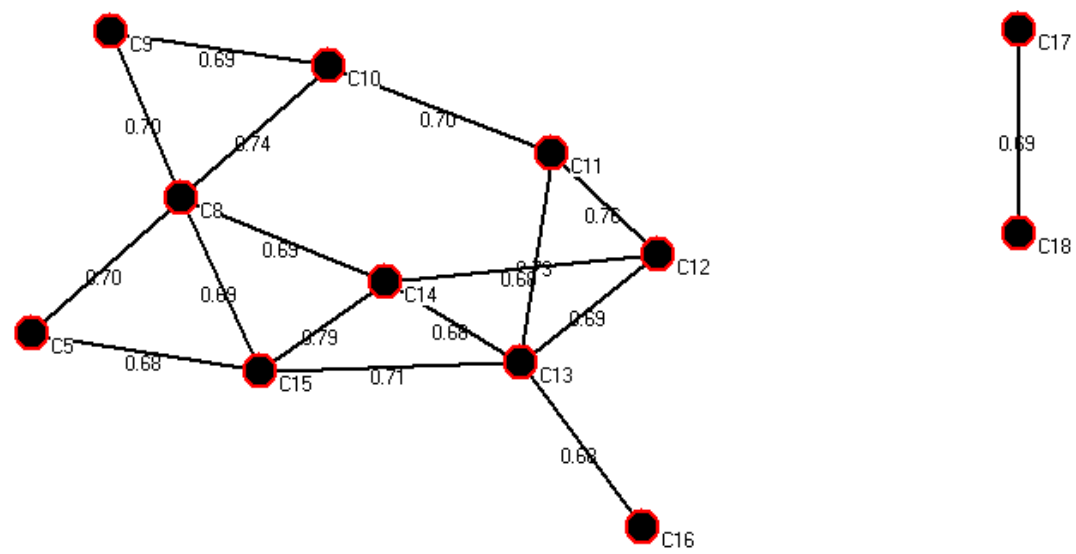

(A)

(B)

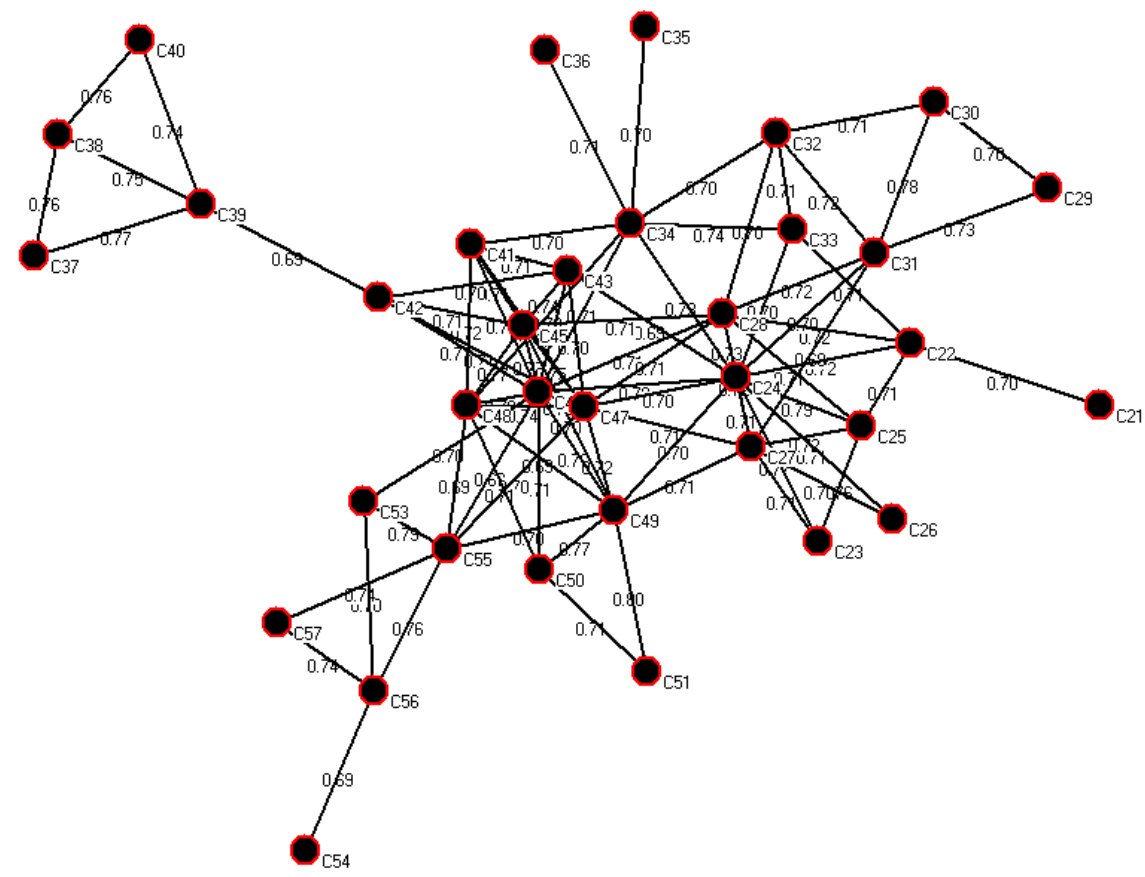

(C)

(D)

Figure 2. Island map of the 43-core risk correlation network. 


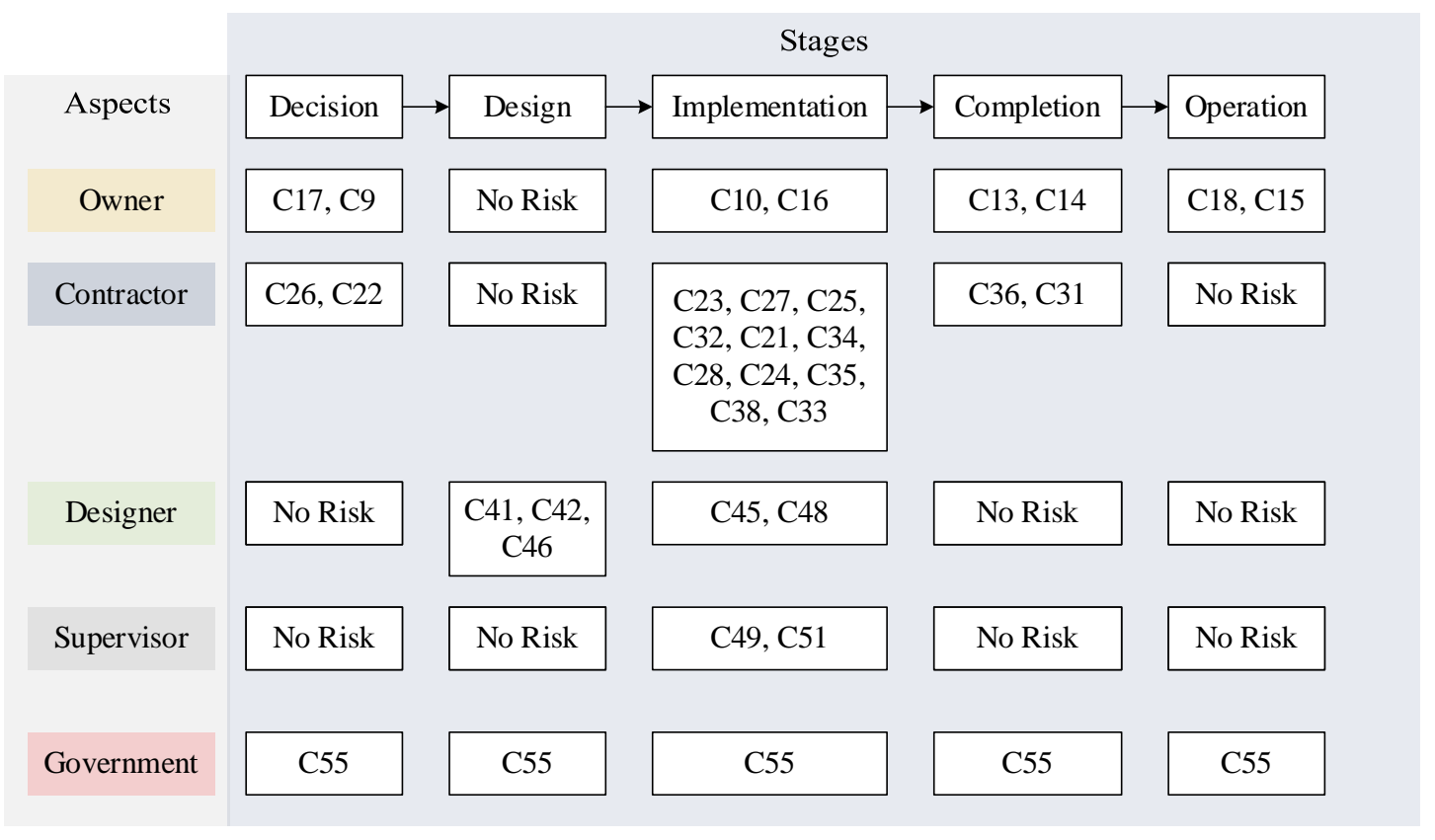

Figure 3. Decisive risks of stakeholders in different stages.

\section{Implications}

Previous studies failed to precisely clarify the risks of green development projects under single stakeholders at different stages. However, the analytical results of this study show that each stakeholder has its own risk control point in the different project stages. In the decision stage, the owner, contractor, and government undertake the risk. The owner must comprehensively consider the project requirements (C9) and prevent overforecasting the project's demand and market share (C17). Potential risks exist for the contractor in underestimating project costs, increasing the quoted price (C22), and having an insufficient understanding of the project requirements, which can cause default (C26). Then, the government has the responsibility of creating extensive laws and regulations (C55) to guarantee that green development projects have legal protection.

In the design stage, only the designer and the government have risk control points. During this stage, risks might occur through design flaws (C41), design changes (C42), and inaccurate estimations of costs (C46). The government retains the same risk as in the decision stage. Moreover, all stakeholders suffer from potential risks in the implementation stage. Insufficient communication and coordination among the participants in the project (C10) and a lack of property management experience can cause operational damage (C16), which are the potential risks of the owner. Failing to achieve the green certification goal, thereby causing claims (C21), a lack of experience managing technical personnel (C23), insufficient experience adopting new materials, technologies, and equipment (C24), insufficient knowledge of green development projects (C25), poor feasibility of the construction method (C27), unstable performance of new materials and equipment (C28), lack of coordination with the designer (C32), increased construction difficulty that generates security risk (C33), project requirements that cause overdue risks (C34), scarcity of green materials that greatly increases the price of green products (C35), and a shortage of insurance for staff and equipment (C38) are the potential risks for the contractor. The designer must be concerned about insufficient innovation in construction and design (C45) and lack of a life cycle assessment in the design (C48). The supervisor risks having a lack of experience in green development project supervision (C49) and insufficient data collection and monitoring (C51). The government has the same risk as in the decision stage. As presented, the contractor has the most responsibility to prevent risks from occurring because there are eleven control points that need to be considered. 
In the completion stage, the designer and the supervisor have no potential risks to control. Nevertheless, the owner's risks are vague responsibilities and certification risks that cause incomplete declaration of the materials. The contractor's risks include insufficient documentation of green materials (C31) and additional requirements for the trial operation (C36). The government has the same risks as those stated in the decision stage. Finally, the owner and the government are the only two risk undertakers in the operations stage. Project contract defects and changes that result in claims (C15) and the project experiencing instability and a lack of scientific maintenance (C18) are the risks for the owner. The government has the same risk as in the decision stage.

In considering all the stages when discussing the pressures of risk absorption, the contractor faces the most pressure, with fifteen risks during an entire green development project. For this reason, the contractor is the key stakeholder who must engage in on-site monitoring of the project. In addition, the contractor must address the needs of the staff for the project, including insurance, safety, working conditions, and compensation, among others. The stakeholder who faces the second most pressure is the owner, who must address at least two risks in all stages except for the design stage. The results also reveal that if the government does not develop complete laws and regulations to ensure that the project runs smoothly, the entire project will suffer from risks regardless of the stage. Thus, the government is an important stakeholder in mitigating the occurrence of risk in a green development project.

Moreover, there are several policy insights are recommended for preventing the risks occurrence of green development project as shown in the following Table 6.

Table 6. The Policy for Preventing the Risks among Stakeholders.

\begin{tabular}{|c|c|c|}
\hline Stakeholders & Stages & Policy for Preventing the Risks \\
\hline \multirow{4}{*}{ Owner } & Decision & $\begin{array}{l}\text { Owner needs to make transparent communications with designers, supervisors } \\
\text { and contractors for ensuring the project can process fluently. }\end{array}$ \\
\hline & Implementation & $\begin{array}{l}\text { Owner musts concentrate on the management of contract divides the duties in } \\
\text { guaranteeing the implementation following the plans. }\end{array}$ \\
\hline & Completion & $\begin{array}{l}\text { Promoting the knowledge of certifications for green development project avoids } \\
\text { the dispute over completion. }\end{array}$ \\
\hline & Operation & $\begin{array}{l}\text { Owner shall enhance the operation maintenance for sticking with the } \\
\text { project goals. }\end{array}$ \\
\hline \multirow{3}{*}{ Contractor } & Decision & $\begin{array}{l}\text { Contractor shall fully understand each complex procedure of project and give the } \\
\text { trainings to technical persons before project started. }\end{array}$ \\
\hline & Implementation & $\begin{array}{l}\text { Contractor needs to participate the government training courses aggressively for } \\
\text { accumulating the knowledge and experiences in terms of green development } \\
\text { project. In addition, it requires having well communications and coordination } \\
\text { with designer. }\end{array}$ \\
\hline & Completion & $\begin{array}{l}\text { Contractor must make the cost following with the pilot investigations and } \\
\text { forecasting effectively and ensures the quotations with reasonable price. }\end{array}$ \\
\hline \multirow[t]{2}{*}{ Designer } & Decision & $\begin{array}{l}\text { Designer shall prevent the changes of original design. Thus, it requires making } \\
\text { double check with owner, contractor and supervisor to eliminate the change } \\
\text { suddenly. If the designer takes the innovation design into the project, it requires } \\
\text { making feasibility study and demonstration adequately. }\end{array}$ \\
\hline & Implementation & $\begin{array}{l}\text { During the implementation stage, designer needs to participate the entire project } \\
\text { period for guaranteeing the construction fulfil the concept of design. }\end{array}$ \\
\hline Supervisor & Implementation & $\begin{array}{l}\text { While the implementation stage, supervisor is required patriating the training } \\
\text { course for reinforcing the knowledge of green development project. } \\
\text { Subsequently, all the reported documentations are required finishing by } \\
\text { the supervisor. }\end{array}$ \\
\hline Government & All the stages & $\begin{array}{l}\text { Government needs to accelerate the related policy establishment in terms of } \\
\text { green development project, standardize the local criteria and clarify the rights } \\
\text { and duties. }\end{array}$ \\
\hline
\end{tabular}




\section{Conclusions}

Belt and Road initiatives in terms of green development projects are attracting increased attention throughout the world. An increasing number of countries want to participate in these initiatives and obtain the co-benefits of sustainability. However, several risks remain for stakeholders when launching such projects. Although previous studies adopted stakeholder theory to discuss project-oriented cases, addressing the risks undertaken from a single stakeholder point of view is insufficient. Thus, this study proposes the employment of SNA to explore the decisive risks for each stakeholder. SNA enables the interrelations among the risks to be considered by structuring a correlation network and providing a visual analysis that then uses $K$-core to screen out unnecessary risks. This process can enable stakeholders to focus on their particular risk control points to guarantee project success.

The contribution of this study can be divided into three parts: (1) providing evidence to support the theoretical basis for enhancing the understanding of the application of theory; (2) offering specific guidelines for green development firms to monitor their projects and prevent the occurrence of risk; and (3) showing that each stakeholder can fulfill its duty by controlling its risks; (4) recommending the related policies for stakeholders in different stage. Furthermore, the project manager can establish a buffer zone based on the results, which provide clear boundaries for making claims once a risk is realized. This study uses stakeholder theory to address the risks involved in green development projects and offers an effective and reliable measure to simplify a complex problem.

The analytical results reveal that stakeholders need to check the control points for potential risks in different project stages. The contractor plays a critical role in mitigating the risks in all stages, given that fifteen risks are present during the decision, implementation, completion, and operation stages. The owner has the second most risks, with eight. Although the government has only one risk throughout an entire project, establishing comprehensive laws and regulations is fundamental to avoiding risk. The supervisor is a low-risk undertaker in a green development project. Furthermore, the key part of a green development project is the implementation stage, which requires that all stakeholders collaborate to mitigate the risk. Subsequently, the operation stage of a green development project has a lower level of risk that the owner and government must consider.

There are several limitations to this study. Although this study attempts to consider the possible risks involved in a green development project, it still not sufficiently comprehensive to reflect actual situations. Thus, future studies should include as many additional potential risks as possible. In addition, a questionnaire is employed in this study, but it lacks an assessment of quantitative data. Integrating qualitative and quantitative data to assess risks should occur in a future study. The sample selected was only from Northeast China, making generalization of the results of this study difficult. To overcome this weakness, all regions in China should be considered in future studies. The proposed analytical procedure can be applied to different cases to provide comparisons among different countries. Finally, future studies could propose hybrid methods to improve the current results based on SNA.

Author Contributions: L.M. and L.W. drafted the idea for this study, and then L.W. conducted the analysis. K.-J.W. revised the content of this study to enhance the readability. M.-L.T. and A.S.F.C. provided guidance on the revisions.

Funding: This study was supported by the National Social Science Fund Project (15BGL023), the National Natural Science Foundation of China (71701029), the Liaoning Academy of Social Sciences Fund (L17BGL019), and Fundamental Research Funds for Central Universities (DUT16RC(3)038).

Conflicts of Interest: The authors declare no conflict of interest. 


\section{Appendix A}

(Basic question * required)

1. Your age is: (single choice * mandatory answer) [single choice] *

$\bigcirc 25$ and under

26-35 years old

○ $36-45$ years old

$\bigcirc 46-55$ years old

56 years old and above

2. The number of green building projects you are involved in is: (single choice * required answer) [single choice] *

$\bigcirc 0-1$

○ $2-5$

○ $6-10$

○ 11-20

$\bigcirc 21$ or more

3. What is your work unit? [single choice] *

University

- Government Department

Tender office

Construction unit

Design Unit

Construction unit

Consultant (including supervision)

Other

4. Your working life in the engineering field (including scientific research) is: [single choice] *

5 years and below

6-10 years

11-15 years

16-20 years

More than 20 years

5. Do you think that the risk of green building projects is comparable to the risk of general projects, and the degree of risk is ( )? [Single choice] *

$\bigcirc$ Far higher than the general project risk

$\bigcirc$ Higher than general project risk

$\bigcirc$ Slightly higher than the general project risk

$\bigcirc$ Same risk as the general project

$\bigcirc$ Lower than the general project risk

6. In your opinion, do the following risk factors related to the owner affect the owner's own risk and the overall risk of the green building project? 1 = very small influence; $2=$ small influence; $3=$ relatively small influence; 4 = general influence; 5 = relatively large influence; 6 = very large influence; 7 = extremely large influence; the numbers 1-7 indicate an increasing risk. [Matrix Question] * 


\begin{tabular}{|c|c|c|c|c|c|c|c|}
\hline & 1 & 2 & 3 & 4 & 5 & 6 & 7 \\
\hline C1 Project funding issues & $\bigcirc$ & $\bigcirc$ & $\bigcirc$ & $\bigcirc$ & $\bigcirc$ & $\bigcirc$ & O \\
\hline C2 Required change of owner & 0 & O & O & O & 0 & 0 & 0 \\
\hline $\begin{array}{l}\text { C3 The green development investment estimate by the owner is } \\
\text { not accurate, leading to unexpected cost overruns }\end{array}$ & O & O & O & $\bigcirc$ & O & 0 & 0 \\
\hline C4 Unreasonable schedule requirements & $\bigcirc$ & $\bigcirc$ & $\bigcirc$ & $\bigcirc$ & O & $\bigcirc$ & O \\
\hline $\begin{array}{l}\text { C5 The requirements of the owner of the green development } \\
\text { project are too high. The location of the project is not accurate }\end{array}$ & $\bigcirc$ & ○ & O & O & ○ & O & 0 \\
\hline C6 The owners have low efficiency & ○ & O & O & $\bigcirc$ & O & $\bigcirc$ & 0 \\
\hline C7 The owners intervene in the construction process unreasonably & O & O & O & O & O & O & O \\
\hline C8 The requirements of the owner contradict & 0 & 0 & 0 & 0 & 0 & 0 & 0 \\
\hline $\begin{array}{l}\text { C9 Insufficient consideration of the green development project } \\
\text { requirements }\end{array}$ & 0 & 0 & 0 & 0 & 0 & 0 & 0 \\
\hline $\begin{array}{l}\text { C10 The owner lacks the ability to coordinate and communicate } \\
\text { with all parties involved in the green development project }\end{array}$ & 0 & 0 & 0 & 0 & 0 & 0 & 0 \\
\hline $\begin{array}{l}\text { C11 The project trial operation cannot meet the requirements of } \\
\text { green certification performance }\end{array}$ & 0 & 0 & 0 & 0 & 0 & 0 & 0 \\
\hline $\begin{array}{l}\text { C12 The evaluation results are not expected to reach the level of } \\
\text { green certification }\end{array}$ & 0 & 0 & 0 & 0 & 0 & 0 & 0 \\
\hline C13 The green certification responsibility is not clear & $\bigcirc$ & $\bigcirc$ & $\bigcirc$ & $\bigcirc$ & $\bigcirc$ & $\bigcirc$ & 0 \\
\hline $\begin{array}{l}\text { C14 The certification risk leads to incomplete materials for green } \\
\text { development declaration }\end{array}$ & 0 & ○ & O & ○ & O & ○ & 0 \\
\hline $\begin{array}{l}\text { C15 The green development project contract has defects or } \\
\text { changes, resulting in claims }\end{array}$ & O & $\bigcirc$ & O & $\bigcirc$ & O & ○ & 0 \\
\hline $\begin{array}{l}\text { C16 The lack of property management experience is harmful to the } \\
\text { green development operation }\end{array}$ & $\bigcirc$ & $\bigcirc$ & 0 & $\bigcirc$ & $\bigcirc$ & ○ & O \\
\hline $\begin{array}{l}\text { C17 The green development project market demand forecast was } \\
\text { incorrect and did not achieve the expected market share }\end{array}$ & O & O & O & 0 & 0 & 0 & 0 \\
\hline $\begin{array}{l}\text { C18 The green development project is unstable and lacks } \\
\text { scientific maintenance }\end{array}$ & 0 & 0 & 0 & 0 & 0 & 0 & 0 \\
\hline $\begin{array}{l}\text { C19 A lack of green development-related insurance products } \\
\text { is evident }\end{array}$ & 0 & 0 & 0 & 0 & 0 & 0 & 0 \\
\hline
\end{tabular}

7. In your opinion, do the following risk factors related to the contractor affect the contractor's own risk and the overall risk of the green building project? 1 = very small influence; 2 = small influence; $3=$ relatively small influence; $4=$ general influence; $5=$ relatively large influence; $6=$ very large influence; 7 = extremely large influence; the numbers $1-7$ indicate an increasing risk. [Matrix Question] *

\begin{tabular}{|c|c|c|c|c|c|c|c|}
\hline & 1 & 2 & 3 & 4 & 5 & 6 & 7 \\
\hline C20 The ability of the contractor is poor & $\bigcirc$ & O & O & O & 0 & 0 & 0 \\
\hline C21 Green goals are the cause of a claim & $\bigcirc$ & $\bigcirc$ & $\bigcirc$ & $\bigcirc$ & O & $\bigcirc$ & O \\
\hline $\begin{array}{l}\text { C22 The contractor underestimated the incremental costs of the } \\
\text { green development project, resulting in an unreasonable } \\
\text { quoted price }\end{array}$ & O & $\bigcirc$ & ○ & $\bigcirc$ & ○ & ○ & 0 \\
\hline $\begin{array}{l}\text { C23 Lack of green construction experience among technical } \\
\text { management personnel }\end{array}$ & O & $\bigcirc$ & ○ & $\bigcirc$ & 0 & ○ & O \\
\hline $\begin{array}{l}\text { C24 The contractor's lack of experience with new materials, new } \\
\text { technology, new equipment applications }\end{array}$ & $\bigcirc$ & $\bigcirc$ & O & $\bigcirc$ & $\bigcirc$ & ○ & 0 \\
\hline $\begin{array}{l}\text { C25 Lack of understanding of green construction, leading to } \\
\text { insufficient attention in management }\end{array}$ & O & $\bigcirc$ & O & $\bigcirc$ & $\bigcirc$ & $\bigcirc$ & O \\
\hline $\begin{array}{l}\text { C26 Insufficient understanding by the owner of the green } \\
\text { requirements, leading to default }\end{array}$ & O & ○ & O & $\bigcirc$ & 0 & ○ & 0 \\
\hline C27 Poor feasibility of the construction method & O & 0 & 0 & $\bigcirc$ & O & 0 & 0 \\
\hline $\begin{array}{l}\text { C28 The performance of new materials/ new equipment is not } \\
\text { sufficiently enough }\end{array}$ & 0 & 0 & 0 & 0 & 0 & 0 & 0 \\
\hline
\end{tabular}




\begin{tabular}{|c|c|c|c|c|c|c|c|}
\hline & 1 & 2 & 3 & 4 & 5 & 6 & 7 \\
\hline C29 Personnel fluidity is large & $\bigcirc$ & $\bigcirc$ & $\bigcirc$ & $\bigcirc$ & $\bigcirc$ & $\bigcirc$ & O \\
\hline C30 The scope of the sub-contract work is poorly defined & O & $\bigcirc$ & $\bigcirc$ & $\bigcirc$ & ○ & $\bigcirc$ & 0 \\
\hline $\begin{array}{l}\text { C31 The application for green development materials needed for } \\
\text { document collection is insufficient }\end{array}$ & $\bigcirc$ & $\bigcirc$ & $\bigcirc$ & $\bigcirc$ & $\bigcirc$ & $\bigcirc$ & O \\
\hline C32 Lack of coordination with design units & O & O & O & O & O & $\bigcirc$ & O \\
\hline $\begin{array}{l}\text { C33 Construction difficulty increases resulting in security risks } \\
\text { when attempting to achieve the energy conservation and } \\
\text { environmental protection requirements of the green development } \\
\text { project }\end{array}$ & O & $\bigcirc$ & O & O & O & O & 0 \\
\hline C34 Green development project requirements with excessive risk & O & O & O & O & O & $\bigcirc$ & 0 \\
\hline $\begin{array}{l}\text { C35 Due to the scarcity of green products, the price of green } \\
\text { materials is too high }\end{array}$ & $\bigcirc$ & $\bigcirc$ & $\bigcirc$ & $\bigcirc$ & O & $\bigcirc$ & O \\
\hline C36 Additional requirements for trial operation & $\bigcirc$ & $\bigcirc$ & $\bigcirc$ & $\bigcirc$ & $\bigcirc$ & 0 & 0 \\
\hline C37 No insurance purchased for the staff and equipment & O & 0 & 0 & O & O & O & O \\
\hline C38 Lack of safety measures and unsafe operation & 0 & 0 & 0 & 0 & 0 & 0 & 0 \\
\hline C39 Warranty risk & O & O & O & O & O & 0 & O \\
\hline C40 Lack of green development-related insurance products & 0 & 0 & 0 & 0 & 0 & 0 & 0 \\
\hline
\end{tabular}

8. In your opinion, do the following risk factors related to the design unit affect the risk of the design unit and the overall risk of the green building project? 1 = very small influence; 2 = small influence; $3=$ relatively small influence; $4=$ general influence; $5=$ relatively large influence; $6=$ very large influence; 7 = extremely large influence; the numbers 1-7 indicate an increasing risk. [Matrix Question] *

\begin{tabular}{|c|c|c|c|c|c|c|c|}
\hline & 1 & 2 & 3 & 4 & 5 & 6 & 7 \\
\hline C41 Design flaws & 0 & 0 & 0 & 0 & 0 & 0 & ○ \\
\hline C42 Design changes & $\bigcirc$ & 0 & 0 & 0 & 0 & 0 & 0 \\
\hline C43 Lack of integration design experience & $\bigcirc$ & 0 & 0 & 0 & 0 & 0 & 0 \\
\hline C44 The risk of green design innovation & 0 & 0 & 0 & 0 & 0 & 0 & O \\
\hline C45 Poor construction of design innovation & 0 & 0 & O & 0 & 0 & 0 & O \\
\hline C46 The cost estimate is insufficient or inaccurate & 0 & 0 & 0 & ○ & 0 & 0 & O \\
\hline $\begin{array}{l}\text { C47 Insufficient on-site investigations resulting in designs that did } \\
\text { not meet local conditions }\end{array}$ & O & ○ & O & ○ & 0 & ○ & O \\
\hline $\begin{array}{l}\text { C48 Lack of participation in the entire life cycle of green } \\
\text { development projects }\end{array}$ & O & 0 & O & O & 0 & O & O \\
\hline
\end{tabular}

9. In your opinion, do the following risk factors related to the supervision unit affect the supervision unit's own risk and the overall risk of the green building project? $1=$ very small influence; $2=$ small influence; 3 = relatively small influence; $4=$ general influence; $5=$ relatively large influence; $6=$ very large influence; $7=$ extremely large influence; numbers 1-7 indicate an increasing risk. [Matrix Question] *

\begin{tabular}{|c|c|c|c|c|c|c|c|}
\hline & 1 & 2 & 3 & 4 & 5 & 6 & 7 \\
\hline $\begin{array}{l}\text { C49 Lack of personnel with experience in green development } \\
\text { supervision }\end{array}$ & O & $\bigcirc$ & $\bigcirc$ & $\bigcirc$ & O & O & 0 \\
\hline $\begin{array}{l}\text { C50 Inadequate understanding and supervision of green } \\
\text { development project, leading to poor supervision and } \\
\text { management on-site }\end{array}$ & O & O & O & $\bigcirc$ & $\bigcirc$ & $\bigcirc$ & 0 \\
\hline $\begin{array}{l}\text { C51 Lack of experience in document management of green } \\
\text { development projects, leading to insufficient data collection for } \\
\text { declaring the green development project }\end{array}$ & $\bigcirc$ & $\bigcirc$ & $\bigcirc$ & $\bigcirc$ & ○ & ○ & 0 \\
\hline C52 Supervision behavior is not standard & $\bigcirc$ & $\bigcirc$ & $\bigcirc$ & 0 & 0 & 0 & 0 \\
\hline
\end{tabular}


10. Do you think that the following risk factors related to government departments affect the overall risk of green building projects? 1 = very small influence; $2=$ small influence; $3=$ relatively small influence; 4 = general influence; 5 = relatively large influence; $6=$ very large influence; 7 = extremely large influence; numbers 1-7 indicate an increasing risk. [Matrix Question] *

\begin{tabular}{|c|c|c|c|c|c|c|c|}
\hline & 1 & 2 & 3 & 4 & 5 & 6 & 7 \\
\hline $\begin{array}{l}\text { C53 The efficiency of government departments is too low and } \\
\text { excessive examinations and approvals are required }\end{array}$ & O & ○ & O & $\bigcirc$ & 0 & 0 & 0 \\
\hline C54 Government intervention in the project is unreasonable & $\bigcirc$ & 0 & $\bigcirc$ & $\bigcirc$ & $\bigcirc$ & 0 & 0 \\
\hline C55 Laws and regulations are not perfect & $\bigcirc$ & O & O & $\bigcirc$ & 0 & 0 & 0 \\
\hline $\begin{array}{l}\text { C56 Lack of a special clause in the contract for the green } \\
\text { development project }\end{array}$ & $\bigcirc$ & O & O & $\bigcirc$ & O & $\bigcirc$ & 0 \\
\hline C57 Policy changes & 0 & 0 & 0 & 0 & O & 0 & 0 \\
\hline
\end{tabular}

If you have other suggestions for this study, please do not hesitate to contact us as we would greatly appreciate your suggestions:

Thank you for your support and participation! 
Table A1. Spearman correlation coefficients.

$\begin{array}{lllllllllllllllllllllllllllllllllllllllllllllllllll}\text { C1 } & \text { C2 } & \text { C3 } & \text { C4 } & \text { C5 } & \text { C6 } & \text { C7 } & \text { C8 } & \text { C9 } & \text { C10 } & \text { C11 } & \text { C12 } & \text { C13 } & \text { C14 } & \text { C15 } & \text { C16 } & \text { C17 } & \text { C18 } & \text { C19 } & \text { C20 } & \text { C21 } & \text { C22 } & \text { C23 } & \text { C24 } & \text { C25 } & \text { C26 } & \text { C27 } & \text { C28 } & \text { C29 }\end{array}$

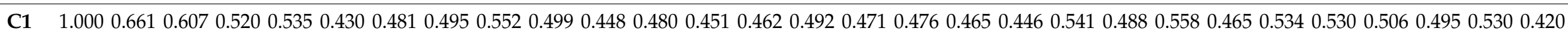

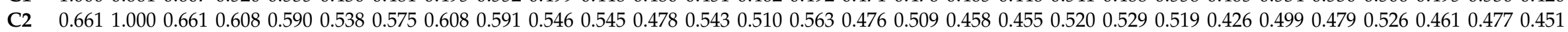

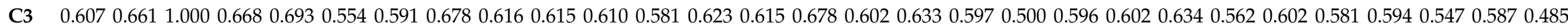

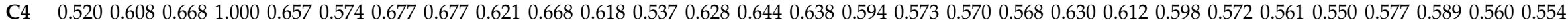

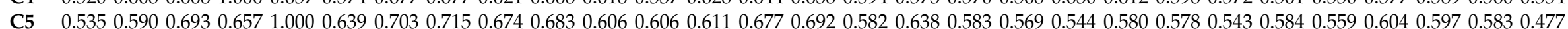

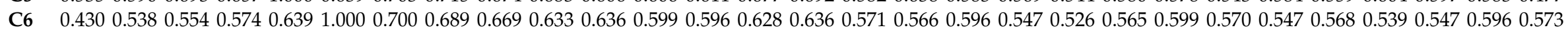

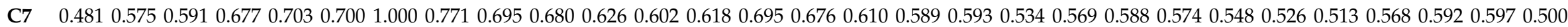

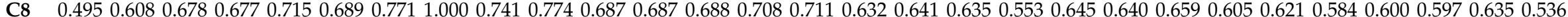

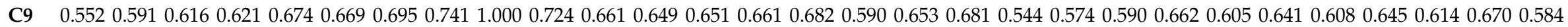

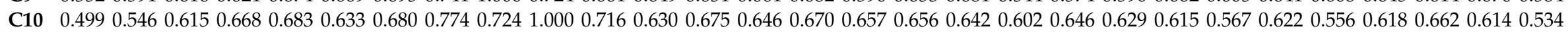

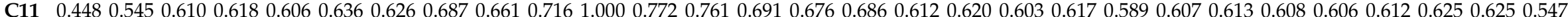

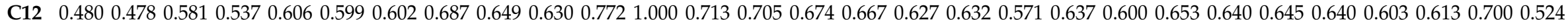

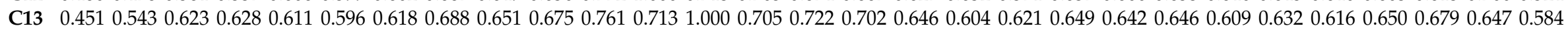

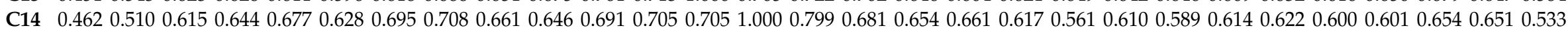

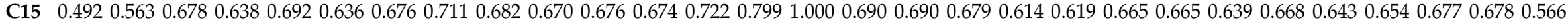

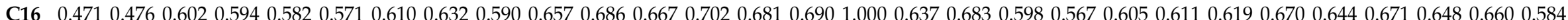

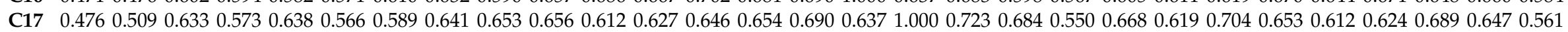

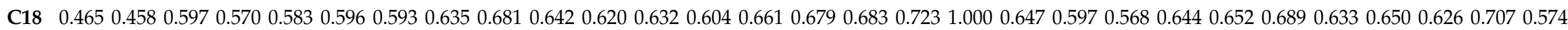

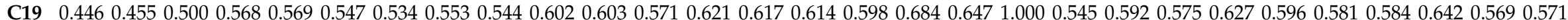

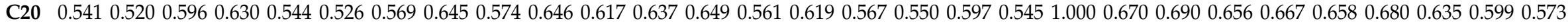

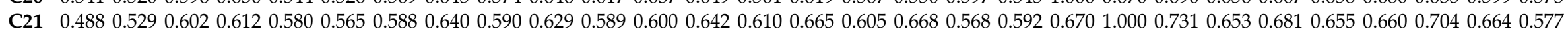

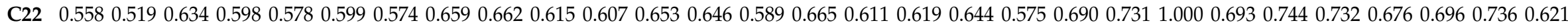

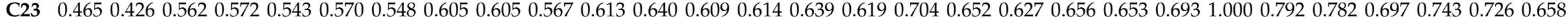

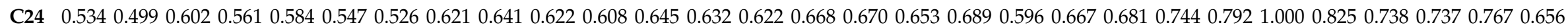

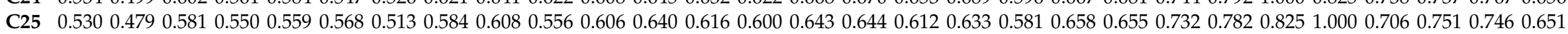

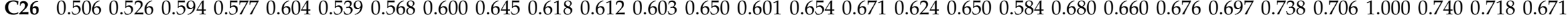

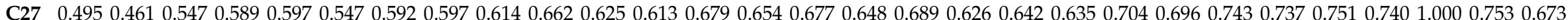

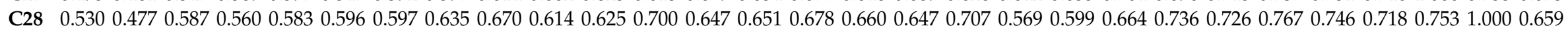

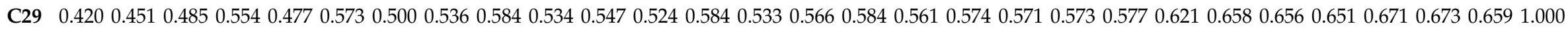
C30 $0.4160 .4950 .5040 .5440 .5400 .5960 .5340 .6220 .606 \quad 0.5880 .5810 .6190 .6240 .5880 .6280 .5360 .5970 .6080 .5300 .6000 .6540 .6960 .6760 .7020 .6800 .7070 .6790 .6980 .728$

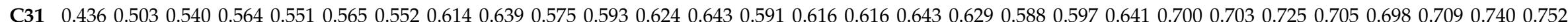

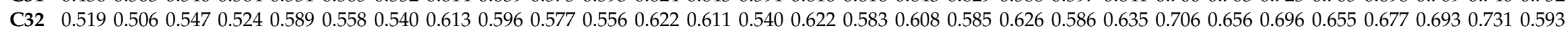

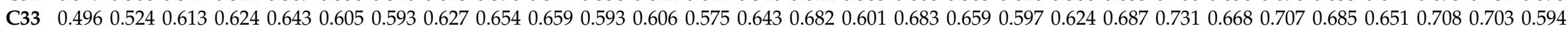

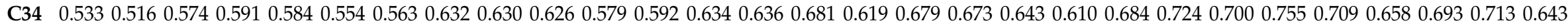

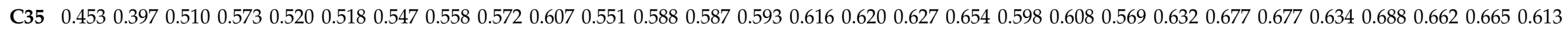


Table A1. Cont.

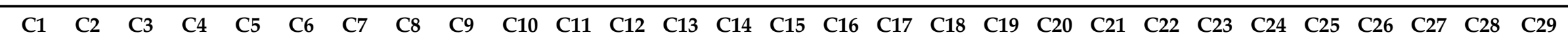

C36 0.4800 .4500 .5260 .6040 .5590 .5480 .5520 .5930 .6130 .6320 .5490 .5800 .5580 .6230 .6500 .5710 .6230 .6660 .5410 .5830 .6300 .6370 .6610 .6500 .6050 .6460 .6700 .6700 .573

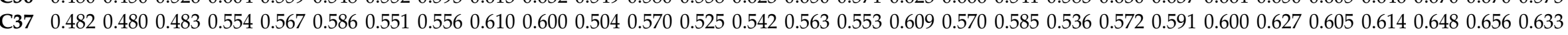

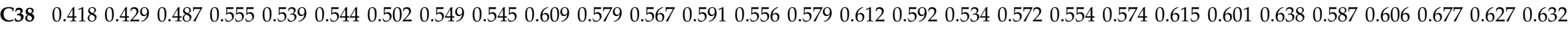

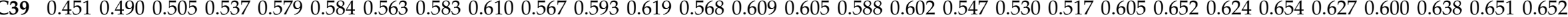

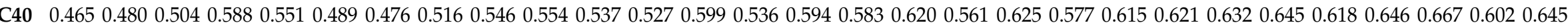

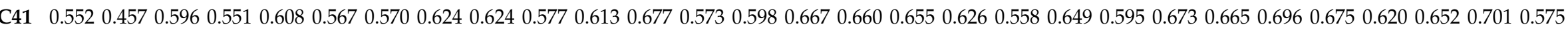

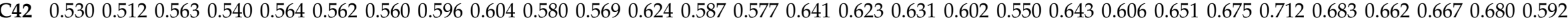

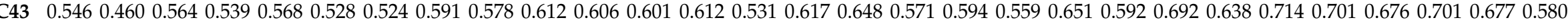

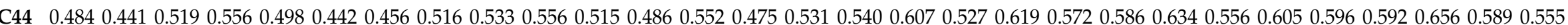

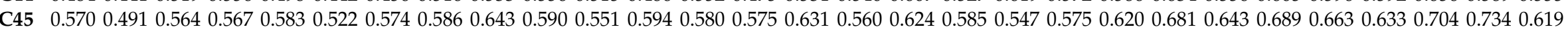

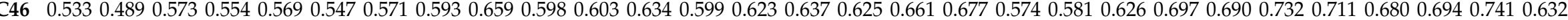

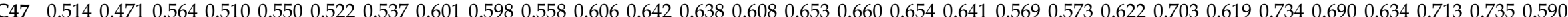

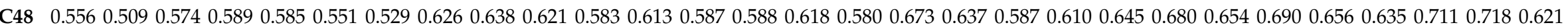

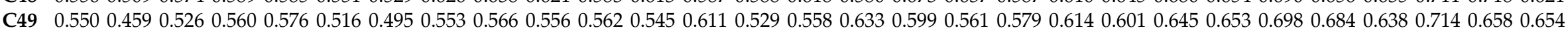

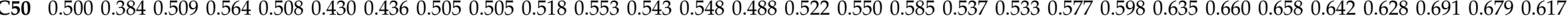

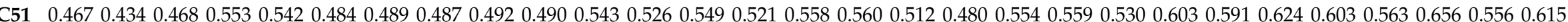

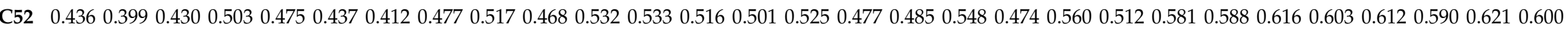

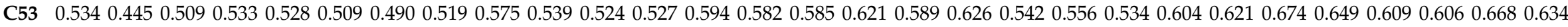

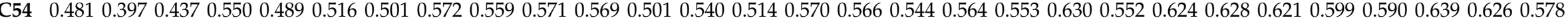

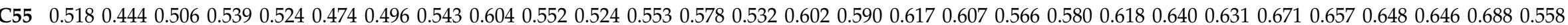

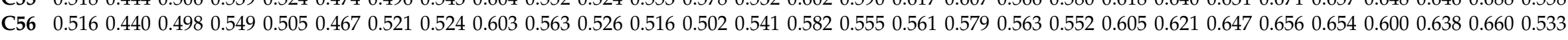
C57 0.5630 .4830 .5030 .5270 .5040 .5350 .5230 .5640 .6240 .5750 .5200 .5120 .5250 .5280 .5880 .5460 .5870 .5630 .5260 .5720 .6110 .6880 .5950 .6670 .6710 .5920 .6310 .6400 .525 
Table A1. Cont.

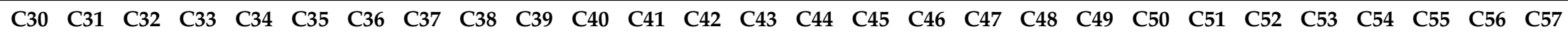

C1 $0.4160 .4360 .5190 .4960 .5330 .4530 .4800 .4820 .4180 .4510 .4650 .5520 .5300 .5460 .4840 .5700 .5330 .5140 .5560 .5500 .5000 .467 \quad 0.4360 .5340 .4810 .5180 .5160 .563$

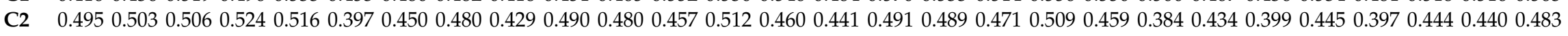

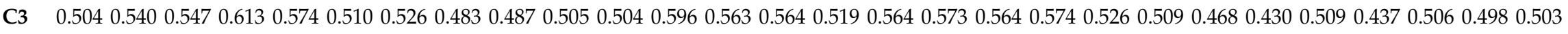

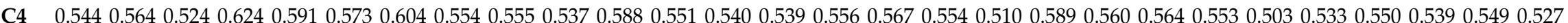

$\begin{array}{lllllllllllllllllllllllllllll}\text { C5 } & 0.540 & 0.551 & 0.589 & 0.643 & 0.584 & 0.520 & 0.559 & 0.567 & 0.539 & 0.579 & 0.551 & 0.608 & 0.564 & 0.568 & 0.498 & 0.583 & 0.569 & 0.550 & 0.585 & 0.576 & 0.508 & 0.542 & 0.475 & 0.528 & 0.489 & 0.524 & 0.505 & 0.504\end{array}$

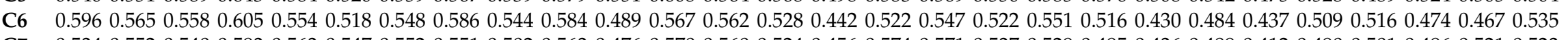

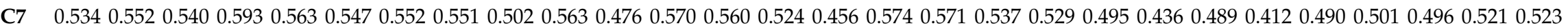

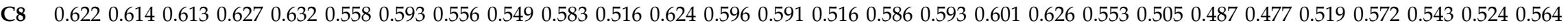

$\begin{array}{lllllllllllllllllllllllllllllll}\text { C9 } & 0.606 & 0.639 & 0.596 & 0.654 & 0.630 & 0.572 & 0.613 & 0.610 & 0.545 & 0.610 & 0.546 & 0.624 & 0.604 & 0.578 & 0.533 & 0.643 & 0.659 & 0.598 & 0.638 & 0.566 & 0.505 & 0.492 & 0.517 & 0.575 & 0.559 & 0.604 & 0.603 & 0.624\end{array}$

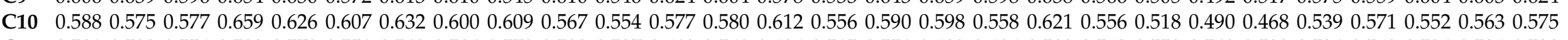

$\begin{array}{llllllllllllllllllllllllllllllll}\text { C11 } & 0.581 & 0.593 & 0.556 & 0.593 & 0.579 & 0.551 & 0.549 & 0.504 & 0.579 & 0.593 & 0.537 & 0.613 & 0.569 & 0.606 & 0.515 & 0.551 & 0.603 & 0.606 & 0.583 & 0.562 & 0.553 & 0.543 & 0.532 & 0.524 & 0.569 & 0.524 & 0.526 & 0.520\end{array}$

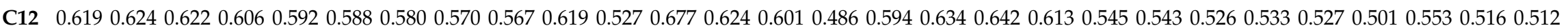

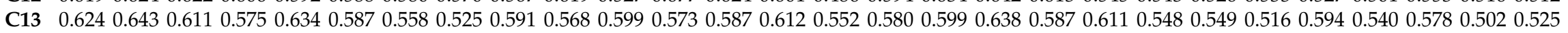

$\begin{array}{llllllllllllllllllllllllllllll}\text { C14 } & 0.588 & 0.591 & 0.540 & 0.643 & 0.636 & 0.593 & 0.623 & 0.542 & 0.556 & 0.609 & 0.536 & 0.598 & 0.577 & 0.531 & 0.475 & 0.575 & 0.623 & 0.608 & 0.588 & 0.529 & 0.488 & 0.521 & 0.501 & 0.582 & 0.514 & 0.532 & 0.541 & 0.528\end{array}$

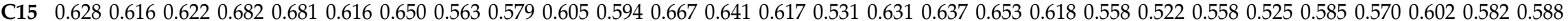

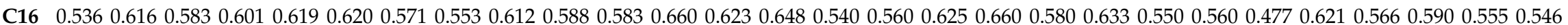

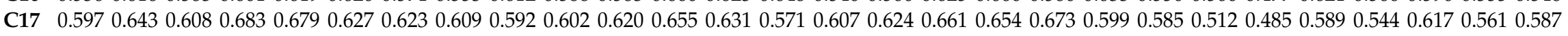

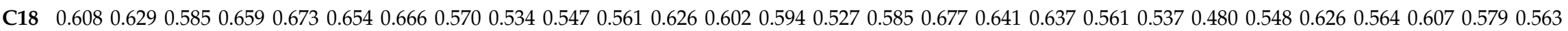

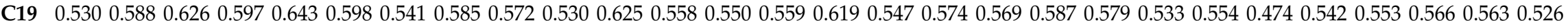

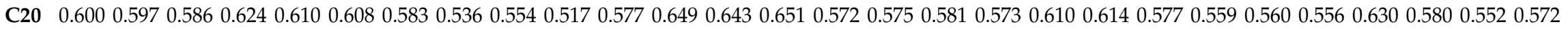

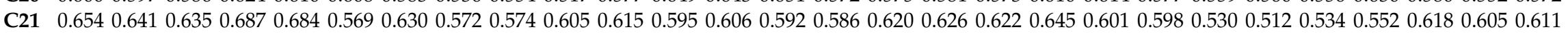

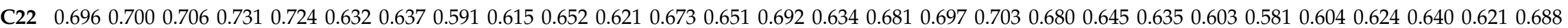

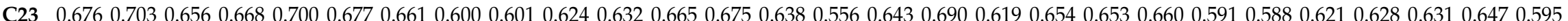

C24 $0.7020 .7250 .6960 .7070 .7550 .6770 .650 \quad 0.6270 .6380 .654 \quad 0.6450 .6960 .7120 .7140 .6050 .6890 .7320 .7340 .6900 .6980 .6580 .6240 .6160 .6740 .6210 .6710 .6560 .667$

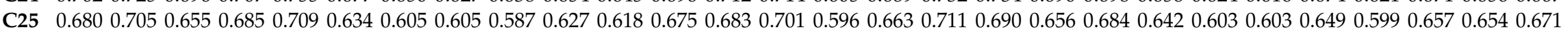

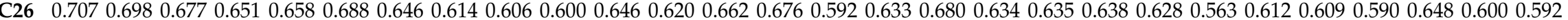

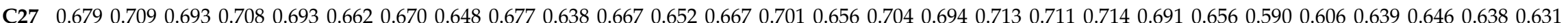

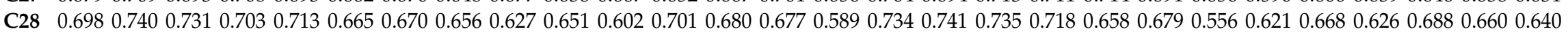

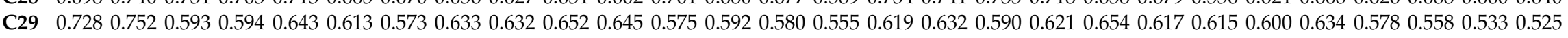

$\begin{array}{lllllllllllllllllllllllllllllll}\text { C30 } & 1.000 & 0.806 & 0.720 & 0.662 & 0.682 & 0.664 & 0.698 & 0.701 & 0.665 & 0.722 & 0.700 & 0.594 & 0.659 & 0.613 & 0.562 & 0.639 & 0.674 & 0.649 & 0.629 & 0.593 & 0.611 & 0.619 & 0.632 & 0.589 & 0.581 & 0.580 & 0.564 & 0.585\end{array}$

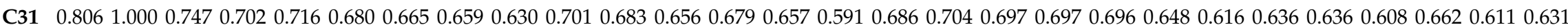

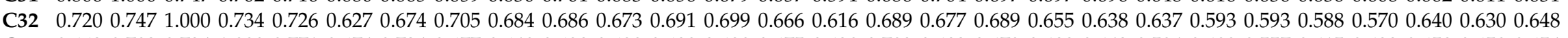

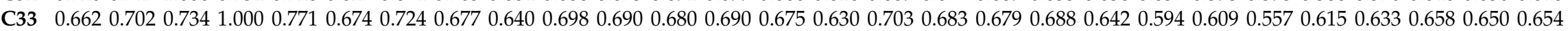

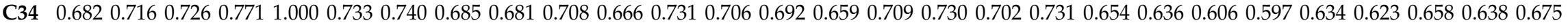

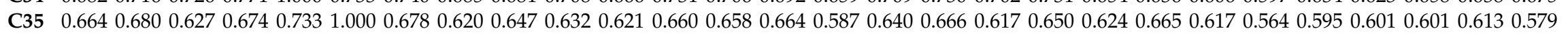


Table A1. Cont.

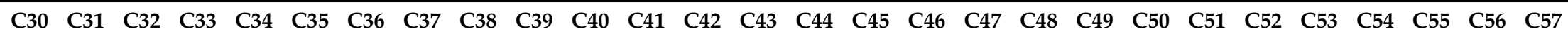

C36 0.6980 .6650 .6740 .7240 .7400 .6781 .0000 .6730 .6250 .6800 .6820 .6070 .6630 .5990 .5550 .6500 .6600 .6370 .6380 .6010 .6330 .5280 .5810 .6410 .5870 .6410 .6450 .633

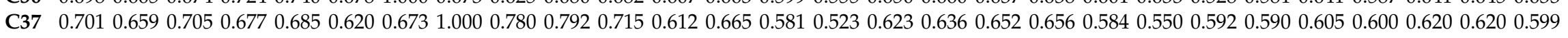
$\begin{array}{llllllllllllllllllllllllllllllll}\text { C38 } & 0.665 & 0.630 & 0.684 & 0.640 & 0.681 & 0.647 & 0.625 & 0.780 & 1.000 & 0.765 & 0.789 & 0.629 & 0.678 & 0.639 & 0.561 & 0.611 & 0.630 & 0.649 & 0.600 & 0.617 & 0.578 & 0.617 & 0.587 & 0.598 & 0.559 & 0.579 & 0.562 & 0.552\end{array}$

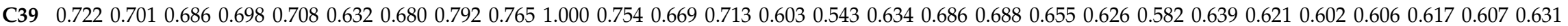

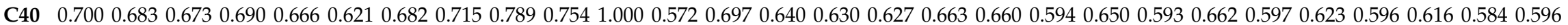

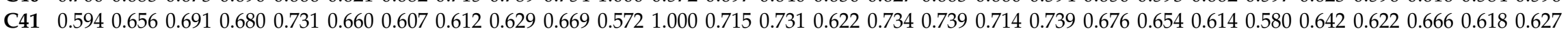

$\begin{array}{llllllllllllllllllllllllllllll}\text { C42 } & 0.659 & 0.679 & 0.699 & 0.690 & 0.706 & 0.658 & 0.663 & 0.665 & 0.678 & 0.713 & 0.697 & 0.715 & 1.000 & 0.728 & 0.663 & 0.726 & 0.749 & 0.744 & 0.688 & 0.672 & 0.629 & 0.685 & 0.571 & 0.640 & 0.603 & 0.667 & 0.609 & 0.652\end{array}$

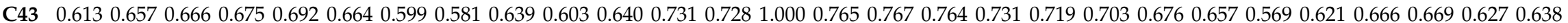

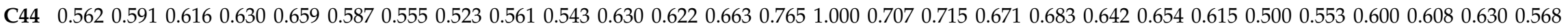

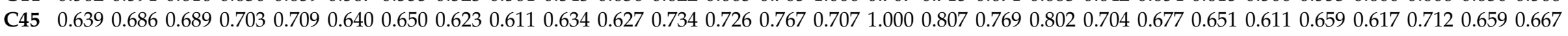

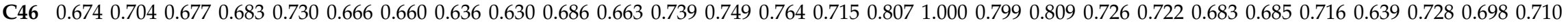

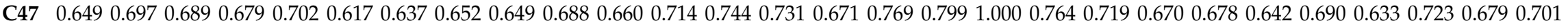

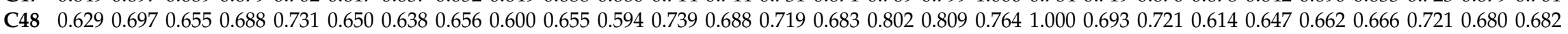

$\begin{array}{lllllllllllllllllllllllllllllll}\text { C49 } & 0.593 & 0.696 & 0.638 & 0.642 & 0.654 & 0.624 & 0.601 & 0.584 & 0.617 & 0.626 & 0.650 & 0.676 & 0.672 & 0.703 & 0.642 & 0.704 & 0.726 & 0.719 & 0.693 & 1.000 & 0.780 & 0.798 & 0.705 & 0.686 & 0.702 & 0.708 & 0.639 & 0.709\end{array}$

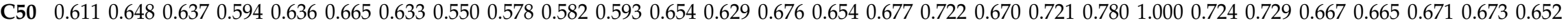

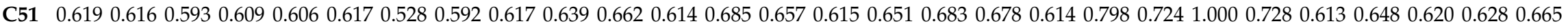

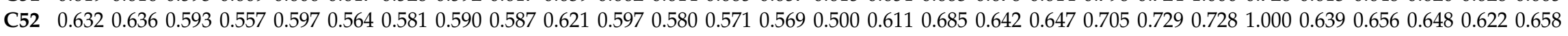

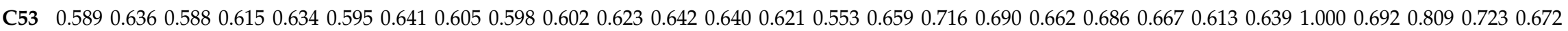

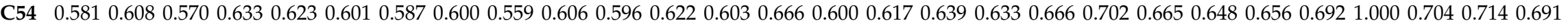

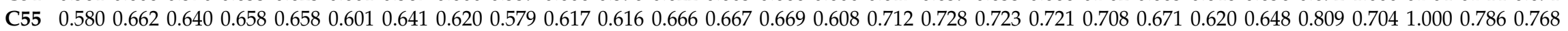

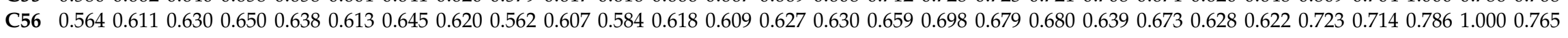

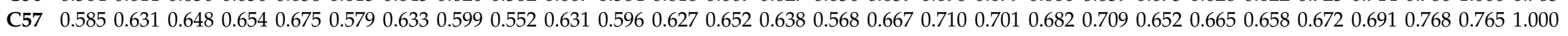




\section{References}

1. $\mathrm{Yu}, \mathrm{H}$. Motivation behind China's 'One Belt, One Road' initiatives and establishment of the Asian infrastructure investment bank. J. Contemp. China 2017, 26, 353-368. [CrossRef]

2. Mitchell, R.K.; Agle, B.R.; Wood, D.J. Toward a theory of stakeholder identification and salience: Defining the principle of who and what really counts. Acad. Manag. Rev. 1997, 22, 853-886. [CrossRef]

3. Yang, R.J.; Zou, P.X.W.; Wang, J. Modelling stakeholder-associated risk networks in green development project. Int. J. Proj. Manag. 2016, 34, 66-81. [CrossRef]

4. Yang, R.J.; Zou, P.X. Stakeholder-associated risks and their interactions in complex green building projects: A social network model. Build. Environ. 2014, 73, 208-222. [CrossRef]

5. Zhao, X.; Hwang, B.-G.; Gao, Y. A fuzzy synthetic evaluation approach for risk assessment: A case of Singapore's green projects. J. Clean. Prod. 2016, 115, 203-213. [CrossRef]

6. Hwang, B.-G.; Shan, M.; Supa'at, N.N.B. Green commercial building projects in Singapore: Critical risk factors and mitigation measures. Sustain. Cities Soc. 2017, 30, 237-247. [CrossRef]

7. Hwang, B.-G.; Zhu, L.; Ming, J.T.T. Factors affecting productivity in green building construction projects: The case of Singapore. J. Manag. Eng. 2016, 33, 04016052. [CrossRef]

8. Bhat, U.; Shrestha, M.; Hébert-Dufresne, L. Exotic phase transitions of k-cores in clustered networks. Phys. Rev. E 2017, 95, 012314. [CrossRef] [PubMed]

9. Yang, Y.; Business, S.O.; University, C.S. Study on audit risk behavior based on stakeholder game analysis. Econ. Geogr. 2016, 6, 88-96.

10. Yang, M.-D.; Lin, M.-D.; Lin, Y.-H.; Tsai, K.-T. Multiobjective optimization design of green building envelope material using a non-dominated sorting genetic algorithm. Appl. Therm. Eng. 2017, 111, 1255-1264. [CrossRef]

11. Zhang, Z.H.; Chen, X.P.; Feng, H.H.; Cheng-Peng, L.U. Study on ecotourism's optimization methods based on stakeholder theory a case study of Dunhuang city. Resour. Dev. Market 2016, 12, 45-56.

12. Kreakie, B.J.; Hychka, K.C.; Belaire, J.A.; Minor, E.; Walker, H.A. Internet-based approaches to building stakeholder networks for conservation and natural resource management. Environ. Manag. 2016, 57, 345-354. [CrossRef] [PubMed]

13. Park, J.; Park, S.; Oh, T. The development of a web-based construction safety management information system to improve risk assessment. KSCE J. Civ. Eng. 2015, 19, 528-537. [CrossRef]

14. Wasserman, S.; Faust, K. Social network analysis in the social and behavioral sciences. In Social Network Analysis: Methods and Applications; Cambridge University Press: Cambridge, UK, 1994; pp. 1-27. 